\title{
La helmintología según la filosofía de la ciencia de Imre Lakatos
}

\section{Helminthology according to the philosophy of science of Imre Lakatos}

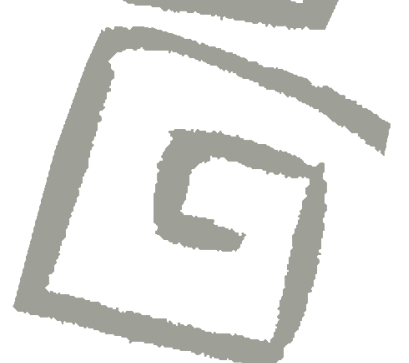

Martín Orensanz ${ }^{1}$, Guillermo Denegri

'Licenciado en Filosofía. Becario doctoral, Consejo de Investigaciones Científicas y Técnicas, con sede en Laboratorio de Zoonosis Parasitarias, Facultad de Ciencias Exactas y Naturales, Universidad Nacional de Mar del Plata, Argentina. $\triangle$ iD

${ }^{2}$ Doctor en Ciencias Naturales. Investigador principal, Consejo de Investigaciones Científicas y Técnicas, con sede en Laboratorio de Zoonosis Parasitarias, Facultad de Ciencias Exactas y Naturales, Universidad Nacional de Mar del Plata, Argentina. $\bowtie$ (iD)
RESUMEN A pesar de que en distintas ramas de la biología se ha utilizado la filosofía de la ciencia de Lakatos, no se ha hecho esto con la helmintología. Aquí utilizamos su metodología de programas de investigación científica (PIC) para reconstruir la historia de la disciplina en cuestión. Sostenemos que el primer PIC de la biología lo inauguró Aristóteles, y en su cinturón protector hay un pequeño grupo de hipótesis auxiliares que se refieren a los helmintos. Ese programa se mantuvo vigente hasta el siglo XVII, época en la que surgen dos PIC rivales en helmintología: el internalista y el externalista. A partir de la segunda mitad del siglo XIX, el PIC internalista fue abandonado, mientras que el externalista amplió considerablemente su cinturón protector durante el siglo XX. El abandono del PIC internalista se debió a los experimentos cruciales de Küchenmeister, que permitieron la consolidación del PIC externalista.

PALABRAS CLAVES Filosofía; Helmintología; Historia.

ABSTRACT Lakatos's philosophy of science has been used for different branches of biology, however this has not been true for helminthology. Therefore, this article examines the possibility of using his methodology of scientific research programmes (SRP) for reconstructing the history of the discipline of helminthology. It is upheld that the first SRP in biology was inaugurated by Aristotle, and its protective belt included a small group of auxiliary hypotheses referring to helminths. This programme continued up until the 17th century, when two rival programmes in helminthology arose: the internalist and the externalist. After the second half of the 19th century the internalist SRP was abandoned, while the externalist considerably broadened its protective belt during the 20th century. The internalist programme was abandoned due to the crucial experiments of Küchenmeister, which permitted the consolidation of the externalist SRP.

KEY WORDS Philosophy; Helminthology; History. 


\section{INTRODUCCIÓN}

Este trabajo forma parte de una investigación mayor titulada "La práctica individual y su relación con la práctica consensuada: el análisis del cambio conceptual en la helmintología", centrada en los aspectos epistemológicos de la helmintología, tema del plan de tesis doctoral en Filosofía de la Universidad Nacional de la Plata de Martín Orensanz, uno de los autores de este artículo

La filosofía de la ciencia de Lakatos $^{(1)}$ se ha utilizado en distintas ramas de la biología, como la genética de poblaciones ${ }^{(2)}$, la biogeografía histórica $^{(3)}$, la ecología ${ }^{(4)}$, la teoría celular ${ }^{(5)}$, la nematología ${ }^{(6)}$, la teoría evolutiva ${ }^{(7,8)}$, el estudio de los priones $^{(9)}$, la parasitología ${ }^{(10,11)}$, la teoría sintética de la evolución ${ }^{(12)}$, los estudios del fitoplancton marino ${ }^{(13)}$, el estudio del componente facial en mamíferos ${ }^{(14)}$, la historia de la medicina tropical ${ }^{(15)}$ y en el examen de la historia de las políticas de la agricultura ${ }^{(16)}$. A pesar de que los trabajos mencionados sobre parasitología, nematología y medicina tropical han utilizado la filosofía de Lakatos para reconstruir algunos aspectos de la historia de esas disciplinas, no se ha intentado reconstruir, al menos de manera esquemática, los principales momentos en la historia de la helmintología desde épocas antiguas hasta el presente.

Existen varios trabajos en torno a la historia de la parasitología en general, en los que se abordan temas que conciernen a la helmintología $a^{(17,18,19,20,21,22,23)}$ pero en ninguno de ellos se ha utilizado la metodología de los programas de investigación científica (PIC) de Lakatos. Aquí ofrecemos una reconstrucción racional, aunque esquemática, de la disciplina en cuestión.

\section{LA FILOSOFÍA DE LA CIENCIA DE LAKATOS Y SU UTILIZACIÓN EN DISTINTAS RAMAS DE LA BIOLOGÍA}

Michod $^{(2)}$ utiliza la filosofía de Lakatos para reconstruir racionalmente la historia de la genética de poblaciones. Sostiene que el núcleo tenaz del PIC de la genética de poblaciones es la afirmación de que la evolución es igual a los cambios en la frecuencia genética de una población. El cinturón protector se compone de modelos matemáticos de los genes, que se fueron desarrollando a partir de la época de la teoría sintética de la evolución en la primera mitad del siglo XX hasta la actualidad. Ese desarrollo permitió predecir nuevos hechos, que luego fueron corroborados, y eso indicaría, para Michod, que el PIC en cuestión es de carácter progresivo. Particularmente, las predicciones concernían a los mecanismos responsables de los cambios en la frecuencia génica de una población; por ejemplo, la selección natural, la migración y la deriva génica, entre otras.

Craw et al.(3) utilizan la filosofía de Lakatos para reconstruir dos PIC distintos en la disciplina conocida como "biogeografía histórica". Estos PIC son el de la "panbiogeografía" y el de la "biogeografía de la vicarianza". En cuanto a la biogeografía conocida como "dispersalista" o "de los centro de origen", Craw et al. sostienen que no se trata de un PIC lakatosiano, porque no tiene la capacidad de realizar predicciones teóricas novedosas. El núcleo tenaz del PIC de la biogeografía de la vicarianza es la afirmación de que los cladogramas biológicos están históricamente conectados entre sí y con los cambios geológicos a través del tiempo. En cambio, el núcleo tenaz del PIC de la panbiogeografía es la afirmación de que las rutas estandarizadas o generalizadas (entendidas como distribuciones geográficas de los taxones) delimitan biotas ancestrales. De los dos PIC que sí reconocen, Craw et al. sugieren que el más progresivo de ellos ha sido el de la panbiogeografía. Este último pudo predecir la conexión transatlántica entre Sudamérica y África, y la existencia de un supercontinente antiguo (Gondwana) formado por África, Madagascar, Australia y la India. Aun así, los autores señalan que el éxito del PIC de la panbiogeografía no está asegurado para siempre ya que, en principio, es posible desarrollar una versión más progresiva del PIC de la biogeografía de la vicarianza. 
Peters ${ }^{(4)}$, en un trabajo acerca de algunas dificultades conceptuales a las que se enfrenta la teoría de las redes tróficas en el contexto de la ecología, examina varias soluciones posibles. Entre ellas, dice que la filosofía de la ciencia de Lakatos podría servir, en principio, como una manera de afrontar las anomalías en esa disciplina. Específicamente se trataría de archivar las anomalías hasta que el PIC tenga, en el futuro, la capacidad de resolverlas; aunque valdría la pena seguir manteniendo dicho PIC si ofrece predicciones novedosas. Pero luego, Peters rechaza la posibilidad de utilizar la propuesta lakatosiana de esa manera, y dice que está más de acuerdo con Karl Popper, en que las hipótesis y las teorías deben ser puestas a prueba de manera rigurosa, sin que la apelación a la capacidad predictiva de dichas hipótesis o teorías pueda servir como excusa para seguir manteniéndolas en medio de una serie de anomalías.

González Recio(5) utiliza la filosofía de Lakatos para reconstruir la teoría celular como un PIC. Parte de una presentación del contexto histórico, que comienza con el descubrimiento de la célula de Robert Hooke en el siglo XVII. Luego narra los principales acontecimientos en el estudio de las células durante el siglo XVIII, hasta llegar a la teoría celular de Schleiden y Schwann en el siglo XIX. Tras reseñar las limitaciones que presentan las filosofías de Popper y de Kuhn para analizar el surgimiento de la citología o teoría celular, González Recio ofrece una interpretación basada en la filosofía de Lakatos. El núcleo tenaz del PIC de Schleiden y Shwann es la afirmación de que las unidades biológicas mínimas de los organismos animales y vegetales son las células. El cinturón protector se fue desarrollando a lo largo de los años subsiguientes y muchos investigadores como Leydig, Schultze y Overton hicieron aportes. Sus hipótesis auxiliares se refieren a los procesos de división celular, a la composición de las células (en la que se incluye el núcleo, la membrana, el citoplasma, etc.) y al modo en que distintas células forman diferentes tejidos.

Schomaker y Been ${ }^{(6)}$ utilizan la filosofía de Lakatos para reconstruir un PIC en la nemato- logía. Sostienen que el trabajo de Seinhorst en nematología puede ser interpretado como un PIC progresivo. A pesar de que utilizan la filosofía de Lakatos, sostienen que Seinhorst desarrolló una filosofía propia de carácter empírico que le da características particulares a su PIC, que no son reducibles a la propuesta lakatosiana. EI PIC de Seinhorst tiene como objetivo principal la búsqueda de métodos que permitan mejorar el rendimiento de los cultivos, sobre la base del estudio científico de las plagas y enfermedades que los afectan, con particular énfasis en el caso de los nematodos parásitos de las plantas. Su heurística positiva permitió desarrollar una serie de modelos matemáticos para las relaciones entre los nematodoes y los cultivos. Por ejemplo, hay varias ecuaciones que utiliza para medir la reducción del crecimiento de los cultivos a lo largo del tiempo debido a la cantidad de nematodos parásitos de determinadas especies. Shomaker y Been concluyen su trabajo diciendo que el PIC de Seinhorst se podría ampliar para abarcar también el estudio de los hongos y de los insectos que afecta a los cultivos.

Dressino et al. ${ }^{(14)}$ utilizan la propuesta lakatosiana para estudiar el estudio del componente facial en mamíferos, retomando trabajos anteriores en los que se habían modificado algunos conceptos de la filosofía de Lakatos. Uno de ellos es el reemplazo del concepto de "núcleo tenaz" por el de "núcleo conservativo". La diferencia consiste en que el núcleo conservativo, a diferencia del núcleo tenaz, puede modificarse como maniobra de último recurso, siempre y cuando las anomalías no puedan ser resueltas desde el cinturón protector. El núcleo conservativo del PIC para el estudio del componente facial en mamíferos afirma que "la morfología del componente facial de mamíferos es la resultante de la interacción de los distintos componentes faciales funcionales frente al estado nutricional y a la adaptación al tipo de dieta", que incluye al herbivorismo, el carnivorismo, el insectivorismo y sus variantes. Denegri ${ }^{(10)}$ reseñó los resultados de aquel trabajo, y afirma que el cinturón protector se compone de cuatro hipótesis auxiliares: "A) hipótesis de la acción de los factores hereditarios sobre 
la ontogenia del componente facial, B) hipótesis del efecto de la nutrición sobre la expresión génica, C) hipótesis de los cambios morfológicos durante el crecimiento, y D) la hipótesis del efecto de la desnutrición sobre la ontogenia facial". Entre las conclusiones que se deducen del PIC, se destaca el hecho de que ciertos árboles filogenéticos requerirían reformulaciones que contemplen no solo criterios genéticos y morfológicos, sino que también consideren los efectos de la malnutrición sobre la morfología.

Silva ${ }^{(7)}$ discute las propuestas de Popper, Kuhn, Lakatos, Feyerabend y otros autores para examinar la historia de la teoría evolutiva, y sostiene que el materialismo dialéctico es más adecuado para analizar la historia de aquella disciplina que las filosofías de la ciencia de los autores mencionados. Dice que el modo en que Lakatos concibe la separación entre la historia interna y externa de la ciencia se enfrenta al problema de no poder explicar, de manera racional, el hecho de que un científico puede adherir a un PIC regresivo por razones políticas y sociales, en vez de científicas. Silva sostiene que ese hecho puede ser explicado racionalmente por el materialismo dialéctico, mientras que Lakatos lo relegaría a la historia externa de la ciencia.

Caponi $^{(15)}$ sostiene que la medicina tropical puede ser considerada como un PIC lakatosiano que se originó a partir de las contribuciones de la microbiología y de la parasitología, pero que con el tiempo se diferenció de esas disciplinas. Analiza el surgimiento de dos de los principales institutos de medicina tropical de la época, el Institut Pasteur de Francia y la London School of Tropical Medicine de Inglaterra. Agrega que el modelo básico de la medicina tropical en esa época era el del vínculo parásito-vector, cuyo ejemplo paradigmático es el de la malaria, aunque también incluye a otros parásitos, como los nematodos del grupo de las filarias. De modo que la medicina tropical se constituye sobre la idea de poder ejercer un control de los vectores que transmiten las enfermedades parasitarias de los trópicos. La malaria, en tanto se trata de un protozoo transmitido por insectos vectores, es el punto principal que diferencia a la medicina tropical de la bacteriología clásica, construida sobre el modelo de las bacterias que se transmiten por el agua o el aire. La heurística positiva se encargó de construir un cinturón protector de múltiples hipótesis auxiliares referidas a los distintos tipos de parásitos tropicales, pero en relación con el modelo de transmisión por insectos vectores.

Zobbe $^{(16)}$ sostiene que la filosofía de la ciencia de Lakatos es útil para analizar la historia de las políticas de investigación en agricultura de EE.UU. A partir de la crisis de la agricultura en la década de 1920 surgen dos PIC rivales en las políticas agrícolas; el primer PIC sostiene la necesidad de que el Estado intervenga en la economía de la agricultura, a través de subsidios y de otros mecanismos y, el segundo, afirma que esto no alcanza, que se debe intervenir en la economía general y abarcar las relaciones de la agricultura con otros sectores económicos. Ambos PIC se mantienen vigentes hasta la década de 1970 momento a partir del cual el primero entra en una fase regresiva y el segundo se mantiene progresivo al incorporar hipótesis predictivas respecto de las políticas de relaciones internacionales para la agricultura estadounidense.

Pidone $^{(9)}$ analiza distintas propuestas en filosofía de la ciencia, incluyendo las de Popper, Kuhn y Lakatos, para examinar la teoría del prión. Su análisis parte del hecho de que las enfermedades conocidas como "encefalitis espongiformes transmisibles" (EET) afectan tanto a los seres humanos como a otros animales. Hay varias teorías que intentan explicar las causas de esas enfermedades, incluyendo la teoría viral, la teoría del virino, la teoría de las moléculas mixtas, la teoría de los nemavirus y la teoría del prión. Actualmente, la explicación más aceptada es esta última. Todas estas teorías, según Pidone, puede ser consideradas como PIC lakatosianos con sus correspondientes núcleos tenaces, cinturones protectores de hipótesis auxiliares, y heurísticas. Agrega también que, a pesar de que la teoría del prión es la explicación más aceptada para la $E E T$, hay ciertos casos en los que esa teoría no es pertinente para realizar predicciones, 
por lo que es legítimo recurrir a las predicciones hechas desde teorías "más pragmáticas", incluyendo algunas de las hipótesis de la virología clásica, por ejemplo.

Denegri(10) utiliza la metodología de Lakatos para formular un PIC en parasitología. Su intención no es identificar un PIC existente en la historia de la disciplina, sino construir uno que pueda servirle a los parasitólogos en su trabajo cotidiano. El núcleo tenaz del PIC afirma que la fauna endoparasitaria de los hospedadores nos permite conocer sus hábitos alimenticios y viceversa. El cinturón protector tiene dos hipótesis: una se refiere a los patrones generales de los ciclos biológicos de los cestodos, trematodos, acantocéfalos y nematodos parásitos de vertebrados. La otra se refiere al desarrollo de comunidades de parásitos basado en cuatro modelos: no-asintótico, equilibrio asintótico, equilibrio no-asintótico, y co-especiación.

Pievani ${ }^{(12)}$ utiliza la filosofía de Lakatos para reconstruir racionalmente la estructura de la teoría sintética de la evolución, también Ilamada "síntesis moderna" o "síntesis evolutiva moderna". Primero distingue una versión "divulgada" o "vulgarizada" de esta teoría, y luego presenta una versión más "realista". La teoría sintética de la evolución, en su versión "vulgarizada", se puede reconstruir como un PIC de la siguiente manera: su núcleo tenaz es la versión neodarwiniana de la selección natural, en tanto hace hincapié en el cambio de la frecuencia genética de las poblaciones. El cinturón protector se compone de tres hipótesis auxiliares principales: i) la hipótesis del gradualismo filético, ii) la hipótesis de que los procesos macroevolutivos se pueden explicar a partir de procesos microevolutivos, y iii) la hipótesis de la posibilidad de utilizar tanto el funcionalismo como el adaptacionismo en tanto explicaciones, según lo requieran los casos particulares. En el resto de su artículo, Pievani ofrece otra posible reconstrucción de la teoría sintética de la evolución como un PIC lakatosiano, aunque de una manera mucho más sofisticada y "realista" que el PIC que utilizó para reconstruir la versión "vulgarizada".
A estos trabajos se podrían agregar muchos otros, como el de Alsina Calvés ${ }^{(8)}$ que analiza la selección natural a partir de distintas filosofías de la ciencia, incluyendo la de Lakatos; el de Nunes-Neto et al. ${ }^{(13)}$ que utiliza la metodología de Lakatos para reconstruir un $\mathrm{PIC}$ en el estudio del fitoplancton marino; el de Sosa ${ }^{(24)}$, que argumenta que a los biólogos les resulta más útil la filosofía de la ciencia de Lakatos que la de Kuhn; y el de Scioscia et al.(11), que corrobora el PIC elaborado por Denegri mediante un análisis de los endoparásitos del zorro gris pampeano.

Nuestra intención aquí no es hacer una revisión exhaustiva de toda la bibliografía especializada en la que se ha utilizado la filosofía de Lakatos en distintas ramas de la biología, ya que eso excedería por completo el marco de este trabajo. Solo nos referimos a los trabajos anteriores con el propósito de ofrecer una muestra representativa y variada. De los trabajos anteriores que se refieren a la parasitología, la medicina tropical y la nematología, no se ha intentado ofrecer una reconstrucción de la historia de la helmintología que parta desde épocas antiguas hasta el presente. Precisamente esta es la tarea que desarrollaremos en el presente trabajo.

\section{LA HISTORIA DE LA HELMINTOLOGÍA DESDE LA FILOSOFÍA DE LA CIENCIA DE LAKATOS}

Podemos decir que el primer PIC de la biología fue propuesto por Aristóteles ${ }^{(25)}$, específicamente en su Investigación acerca de los animales. Lakatos ${ }^{(1)}$ no parece haber considerado esta posibilidad ya que, al igual que Kuhn ${ }^{(26)}$, sitúa la aparición de los primeros PIC (o paradigmas en el caso de Kuhn) en el siglo XIX, con las obras de Darwin y Mendel. Pero ni Lakatos ni Kuhn le dedicaron demasiada atención a la historia de la biología, sino que se concentraron en la historia de la astronomía, la física, la química y la matemática.

El núcleo tenaz del PIC aristotélico parece ser la afirmación de que en la naturaleza, 
los seres vivos se organizan de manera jerárquica siguiendo una "escala natural" que parte desde los organismos considerados "inferiores" hasta llegar al ser humano. Los invertebrados, como los gusanos, los moluscos, los crustáceos y los insectos ocupan los escalones inferiores. Ascendiendo en complejidad, se encuentran los peces, los anfibios y reptiles, las aves, los mamíferos y por último, los seres humanos.

El cinturón protector se compone de una cantidad enorme de hipótesis auxiliares, algunas referidas a todos los grupos animales, y otras a cada grupo específico. Dentro de las hipótesis auxiliares del PIC aristotélico, se destaca un pequeño conjunto que se refieren a los helmintos. La primera hipótesis auxiliar es de índole morfológica: dice que los gusanos en general son animales ápodos, sin ojos ni boca, de cuerpo blando y sin esqueleto. La segunda, referida a los helmintos, es de índole taxonómica o clasificatoria, y dice que existen tres tipos de helmintos: aquellos que son largos y planos (las lombrices solitarias), aquellos que son redondos y cortos (los nematodos), y los ascáridos (que hoy sabemos que son un grupo dentro de los nematodos). No está del todo claro por qué Aristóteles distingue a los ascáridos de los otros nematodos. La tercera y última hipótesis auxiliar para este grupo de animales es de índole generativa. Dice que todos los gusanos surgen por generación espontánea, a partir de la materia putrefacta, como la carne podrida o los alimentos descompuestos en el intestino.

Durante la Edad Media, el PIC aristotélico no sufrió modificaciones sustanciales, aunque se lo amplió un poco con la incorporación de algunos nuevos descubrimientos. En lo que se refiere a los helmintos, en la Edad Media se descubren los trematodos, que al parecer eran desconocidos para los autores de la antigüedad grecorromana. Los trematodos fueron descubiertos por Jean de Brie en 1379. Su incorporación al PIC aristotélico no resultó problemática, ya que se consideró que se trataba simplemente de un grupo de gusanos parásitos que hasta el momento no se conocían. Solo hubo que modificar la hipótesis auxiliar taxonómica para incluirlos.
A partir del siglo XVII surgen dos PIC rivales. Farley ${ }^{(27)}$ ha señalado que el debate en esa época entre la comunidad de los helmintólogos polarizaba a dos grupos. A unos los denomina "internalistas", y a los otros "externalistas". Los internalistas sostenían que los helmintos se generan de manera espontánea dentro del cuerpo del hospedador. Por ejemplo, se creía que las lombrices solitarias surgían espontáneamente en el intestino a partir de los alimentos mal digeridos. Así pensaba William Ramsay ${ }^{(28)}$, quien además propuso el término "helmintología" en 1668 para caracterizar a la disciplina científica que estudia a los helmintos. Francesco Redi(29), quien ofreció la primera refutación de la hipótesis de la generación espontánea de los insectos, también tenía una postura internalista con respecto a los gusanos parásitos. A través de una serie de experimentos, este autor mostró que las larvas y las moscas que se observan en la carne podrida no surgen por generación espontánea, sino por huevos depositados provenientes de moscas progenitoras. Pero en lo que se refiere a los helmintos intestinales como las lombrices solitarias, Redi adhirió a la tesis internalista, es decir, creía que se generaban de manera espontánea en el intestino. Es interesante destacar que Redi se adelantó casi 200 años a los experimentos de Pasteur que refutaron la teoría de la generación espontánea. Como naturalista, Redi sospechaba que la generación espontánea no era el modo en que surgen nuevos organismos, al menos no los insectos como las moscas que comúnmente se observan en la carne podrida.

Los externalistas, en cambio, negaban la hipótesis de la generación espontánea, y afirmaban que los helmintos entran al hospedador desde el medio externo. Edward Tyson $^{(30)}$ y Antony van Leeuwenhoek ${ }^{(31)}$ son representantes de este grupo. Tyson diseccionó varios ejemplares de nematodos y mostró que tienen órganos sexuales, motivo por el cual sugirió que se reproducen de manera sexual en el intestino del hospedador, tras haber ingresado desde el medio externo. Leeuwenhoek, por su parte, sostuvo que todos los helmintos se encuentran en 
el medio externo, pero en miniatura, y Leeuwenhoek creía que tras ingresar al hospedador de alguna manera (por ejemplo, a través de la respiración), los helmintos en miniatura aumentan de tamaño hasta convertirse en gusanos visibles a simple vista.

La caracterización que Farley ${ }^{(27)}$ hace de estos dos grupos de investigadores se puede interpretar a partir de la filosofía de la ciencia de Lakatos como la diferencia entre dos PIC rivales. El núcleo tenaz del PIC internalista es la afirmación de que los helmintos surgen por generación espontánea. Aquí hay una diferencia importante con respecto al PIC en biología que había inaugurado Aristóteles. El PIC aristotélico abarca a todos los animales, y su núcleo tenaz se refiere a la "escala de la naturaleza". Para los helmintos, hay un pequeño grupo de hipótesis auxiliares en el cinturón protector, en el que se encuentra la hipótesis de la generación espontánea. En el PIC internalista, en cambio, la generación espontánea ya no es una hipótesis auxiliar del cinturón protector, sino el núcleo tenaz del PIC. El cinturón protector se compone de un número considerable de hipótesis auxiliares, cuya formulación extensa y detallada se puede encontrar en la obra de William Ramsay. En su libro Elminthologia, Ramsay propone una serie de hipótesis que explican cómo es que distintos desequilibrios humorales originan distintos tipos de helmintos. A esto le agrega el tipo de alimento ingerido, la "buena" o "mala" digestión del hospedador, e incluso influencias climáticas tales como el calor y el frío. Todos estos factores, y muchos otros, le servían al PIC internalista como explicaciones acerca de la generación espontánea de los helmintos.

EI núcleo tenaz PIC externalista es la afirmación de que los helmintos ingresan al hospedador a través del medio externo. El cinturón protector se compone de varias hipótesis auxiliares que indican las posibles vías de entrada, tales como a través de la respiración, o de los alimentos, o del agua ingerida, o incluso a través de los poros de la piel, si se considera, como lo hacía Leeuwenhoek, que el tamaño de los helmintos en el medio externo es microscópico.
El debate entre estos dos PIC duró hasta la segunda mitad del siglo XIX, época en la que Friedrich Küchenmeister realizó su famoso y controvertido experimento que consistía en administrarle larvas de cestoda (específicamente cisticercos de Taenia solium) a presos condenados a muerte. Tras la ejecución de los prisioneros, Küchenmeister diseccionó sus cadáveres y encontró cestodos adultos en ellos. A pesar de la ola de controversias éticas que sus experimentos suscitaron, los resultados de Küchenmeister fueron interpretados como una refutación definitiva de la tesis de la generación espontánea de los helmintos. Pero esta interpretación de sus resultados no ocurrió inmediatamente, sino que tardó varios años en instalarse.

En la filosofía de Lakatos hay ciertas consideraciones polémicas en torno a este tipo de "experimentos cruciales" que nos permiten elaborar algunas reflexiones al respecto. Lakatos dice que un "experimento crucial" nunca es inmediatamente interpretado como tal en el momento histórico en el que se lo realiza, sino que es reconocido como "crucial" mucho después, por parte de los historiadores que reconstruyen los principales momentos de la disciplina científica que estudian. Si esto es así, entonces los experimentos de Küchenmeister no habrían sido reconocidos como cruciales sino hasta mucho después. Nos parece que este punto de la filosofía de Lakatos es discutible. Sin embargo, sin entrar en una discusión detallada al respecto, podemos señalar que si aceptamos esta tesis, entonces se puede interpretar la ola de controversias éticas en torno a los experimentos de Küchenmeister como una muestra de que el PIC internalista todavía no había perdido todo el apoyo de la comunidad de los helmintólogos.

No estamos argumentando que el ejemplo analizado refuta la concepción de Lakatos, sino más bien todo lo contrario. El ejemplo de Küchenmeister en realidad da soporte a la perspectiva lakatosiana, justamente porque muchos helmintólogos continuaron adhiriendo al PIC internalista. Küchenmeister no realizó un "experimento crucial aislado", sino que su trabajo permitió que se consolidara el 
PIC externalista. Esto no se debió solamente a una cuestión de tiempo, sino que el PIC externalista pudo aumentar su base empírica al mostrar que T. solium ingresaba al hospedador desde el medio externo. Desde un punto de vista historiográfico, podemos decir que esto se convirtió en una anomalía para el PIC internalista.

De ser cierta la tesis de Lakatos en torno a los experimentos cruciales, significaría que la apreciación del trabajo de Küchenmeister tuvo lugar recién en el siglo XX. Pero lo que habría que determinar es si esa apreciación se hizo desde el PIC externalista, que habría continuado vigente hasta nuestros días, o si ocurrió en el contexto de un PIC nuevo y distinto. Determinar esto exigiría un nuevo trabajo, pero podemos suponer, al menos como hipótesis de trabajo historiográfico, que no surgió un nuevo PIC en el siglo XX, sino que se amplió y refinó el PIC externalista heredado de la Época Moderna. El núcleo tenaz se habría mantenido intacto, pero habrían ocurrido importantes cambios en su cinturón protector de hipótesis auxiliares. Para empezar, se habría eliminado la hipótesis auxiliar de que los helmintos pueden ingresar al hospedador por vía respiratoria. Además, también se habría eliminado la hipótesis según la cual los helmintos se encuentran en el medio externo en forma de miniatura. En vez de ello, la dilucidación del ciclo biológico de los cestodos, trematodos y nematodos en el siglo XIX y principios del XX habría permitido reemplazar esa hipótesis de los "helmintos en miniatura" por una hipótesis basada en la descripción completa de los sucesivos estadios larvales de sus ciclos de vida.

\section{CONCLUSIÓN}

La metodología de Lakatos es útil para reconstruir racionalmente la historia de la helmintología sobre la base de la identificación de sucesivos PIC. Aún así, es necesario introducir una modificación en la propuesta de dicho filósofo. En vez de considerar que los primeros PIC de la biología se formaron en el siglo XIX con Darwin y Mendel, parece más adecuado sostener que el primer PIC de la biología fue inaugurado por Aristóteles. En ese PIC, cuyo cinturón protector cuenta con una cantidad enorme de hipótesis auxiliares que se refieren a todos los grupos de animales, habría un pequeño conjunto de hipótesis que se refieren a los helmintos. Interesa resaltar, particularmente, la hipótesis auxiliar que afirmaba que los helmintos surgen por generación espontánea.

La caracterización que Farley hace respecto de los helmintólogos "internalistas" y "externalistas" durante la Época Moderna se puede interpretar como la diferencia entre dos PIC rivales. Hemos visto que el PIC internalista se diferencia del PIC aristotélico en tanto que la generación espontánea ya no es una hipótesis auxiliar del cinturón protector del PIC antiguo, sino el núcleo tenaz de un nuevo PIC específicamente limitado al campo de la helmintología, y no al de la biología o zoología en general.

Por último, la tesis de Lakatos respecto de los experimentos cruciales nos permite reflexionar acerca del alcance que tuvieron los trabajos de Küchenmeister en la segunda mitad del siglo XIX. De ser cierta la tesis de Lakatos, esto significaría que Küchenmeister no le habría asestado el "golpe definitivo" al PIC internalista, sino que este último se habría mantenido activo durante cierto tiempo. Esto permitiría explicar por qué varios helmintólogos siguieron suscribiendo a la explicación basada en la generación espontánea durante esa época. Es decir, mientras el PIC externalista se consolidaba con los trabajos de Küchenmeister al aumentar su base empírica, al PIC internalista le resultaba cada vez más difícil explicar los éxitos de su rival.

Aquí solo hemos planteado los aspectos más generales de la historia de la helmintología con base en la filosofía de la ciencia de Lakatos. Para trabajos futuros, será necesario profundizar y detallar varios aspectos de esa reconstrucción racional. Por ejemplo, será necesario considerar qué impacto tuvo la taxonomía de Linneo para la helmintología del siglo XVIII, qué influencia tuvieron Lamarck y Darwin en la helmintología del siglo XIX, y 
qué aspectos de la teoría sintética de la evolución, la genética, la ecología, y la biología molecular, entre otras disciplinas, afectaron el cuerpo de conocimientos de la helmintología del siglo XX y principios del XXI.

\section{AGRADECIMIENTOS}

Este trabajo fue posible gracias a la Beca Interna Doctoral del Consejo Nacional de Investigaciones Científicas y Técnicas (CONICET) otorgada al Licenciado Orensanz (período 2015-2019), y al financiamiento obtenido a través de los siguientes subsidios de investigación: Universidad Nacional de Mar del Plata (EXA764/16) y Consejo Nacional de Investigaciones Científicas y Técnicas (PIP No 0029).

\section{REFERENCIAS BIBLIOGRÁFICAS}

1. Lakatos I. La metodología de los programas de investigación científica. Madrid: Alianza Editorial; 1983.

2. Michod R. Positive heuristics in evolutionary biology. The British Journal of Philosophy of Science. 1981;32(1):1-36.

3. Craw RC, Weston P. Panbiogeography: A progressive research program? Systematic Biology. 1984;33(1):1-13.

4. Peters RH. Some general problems for ecology illustrated by food web theory. Ecology. 1988;69(6):1673-1676.

5. González Recio JL. Elementos dinámicos de la teoría celular. Revista de Filosofía. 1990;3(4):83-109.

6. Schomaker $\mathrm{CH}$, Been TH. The Seinhorst Research Program. Fundamental and Applied Nematology. 1998;21(5):437-458.

7. Silva EP. A short history of evolutionary theory. História, Ciencias, Saúde - Manguinbos. 2001;III(3):671-687.

8. Alsina Calvés J. Modelos de cambio científico a partir de la selección natural: análisis y propuestas. ILUIL. 2006;29(64):221-257.
9. Pidone CL. La teoría del prión. Analecta Veterinaria. $2005 ; 25(2): 62-72$.

10. Denegri G. Fundamentación epistemológica de la parasitología. Mar del Plata: EUDEM; 2008.

11. Scioscia N, Beldoménico P, Denegri G. Contrastación de un programa de investigación científica progresivo en parasitología: los endoparásitos del zorro gris pampeano Lycalopex gymnocercus. Filosofia e História da Biología. 2016;11(1):107-120.

12. Pievani T. An evolving research programme: The structure of evolutionary theory from a Lakatosian perspective. In: Fascolo A, (ed.). The theory of evolution and its impact. Berlin: SrpingerVerlag; 2011. p. 211-228.

13. Nunes-Neto NF, Santos do Carmo R, El-Hani $\mathrm{CN}$. The relationships between marine phytoplankton, dimethylsuphide and the global climate: The CLAW hypothesis as a Lakatosian progressive problemshift. In: Kersey WT, Munger SP, (eds.). Marine phytoplankton. New York: Nova Science Publishers; 2009.

14. Dressino V, Denegri G., Lamas SG. ¿Es posible una propuesta lakatosiana para el estudio del componente facial en mamíferos? Episteme. 1998;3(5):73-87.

15. Caponi S. Coordenadas epistemológicas de la medicina tropical. História, Ciencias, Saúde Manguinhos. 2003;10(1):113-149.

16. Zobbe $\mathrm{H}$. On the foundation of agricultural policy research in the United States. Acta Agriculturae Scandinavica Section C - Food Economy. 2004; 1(1):34-45.

17. Amici RR. The history of Italian parasitology. Veterinary Parasitology. 2001;98(1): 3-30.

18. Cordero Del Campillo M. The history of veterinary parasitology in Spain. Veterinary Parasitology. 1989;33(1):93-116. 
19. Cox FE. History of human parasitology. Clinical Microbiology Reviews. 2002;15(4):595-612.

20. Enigk K, Habil HC. History of veterinary parasitology in Germany and Scandinavia. Veterinary Parasitology. 1989;33(1):65-91.

21. Grove DI. A history of human helminthology. Wallingford: CAB International; 1990.

22. Hoeppli R. The knowledge of parasites and parasitic infections from ancient times to the 17 th century. Experimental Parasitology. 1956;5(4):398-419.

23. Touratier L. History of veterinary parasitology in France. Veterinary Parasitology. 1989;33(1):45-63.

24. Sosa R. ¿Por qué a los biólogos les sirve más Lakatos que Kuhn? Centro de Estudios Filosóficos de Salta: Temas de Filosofía. 2012;15:175-184.

25. Aristóteles. Investigación sobre los animales. Madrid: Editorial Gredos; 1992.

26. Kuhn TS. The structure of scientific revolutions. 2nd ed. Chicago: University of Chicago Press; 1970.
27. Farley J. The spontaneous generation controversy (1700-1860): The origin of parasitic worms. Journal of the History of Biology. 1972;5(1):95-125.

28. Ramsay W. Elminthologia, or some physical considerations of the matter, origination, and several species of wormes macerating and direfully cruciating every part of the bodies of mankind. London: John Streater; 1668.

29. Redi F. Experiments on the generation of insects (Translated from the Italian Edition of 1688 by $\mathrm{M}$. Bigelow). Chicago: The Open Court Publishing Company; 1909.

30. Tyson E. Lumbricus Latus, or a discourse read before the Royal Society of the Joynted Worm. Philosophical Transactions of the Royal Society. 1683;13:113-144.

31. Leeuwenhoek A. The select works of Anthony van Leeuwenhoek: containing his microscopical discoveries in many of the works of nature (vol 1). London: Black Horse Court, Fleet Street; 1800.

FORMA DE CITAR

Orensanz M, Denegri G. La helmintología según la filosofía de la ciencia de Imre Lakatos. Salud Colectiva. 2017;13(1):139-148. doi: 10.18294/sc.2017.1134.

Recibido: 11 de septiembre de 2016 | Versión final: 5 de diciembre de 2016 | Aprobado: 29 de diciembre de 2016

Este obra está bajo una licencia de Creative Commons Reconocimiento-NoComercial 4.0 Internacional. Reconocimiento - Permite copiar, distribuir y comunicar públicamente la obra. A cambio, se debe reconocer y citar al autor original. No Comercial - Esta obra no puede ser utilizada con finalidades comerciales, a menos que se obtenga el permiso.

http://dx.doi.org/10.18294/sc.2017.1134 